\title{
Effects of Cognitive Reappraisal on Subjective and Neural Reactivity to Angry Faces in Children with Social Anxiety Disorder, Clinical Controls with Mixed Anxiety Disorders and Healthy Children
}

\author{
Verena Keil $^{1} \cdot$ Brunna Tuschen-Caffier $^{1} \cdot$ Julian Schmitz ${ }^{2,3}$ (D)
}

Accepted: 13 April 2021 / Published online: 24 April 2021

(c) The Author(s) 2021

\begin{abstract}
Cognitive models of social anxiety suggest that social anxiety disorder (SAD) is characterized by both enhanced emotional reactivity and deficits in emotion regulation. Emotional reactivity to socially threatening children's faces and their modulation through reappraisal were measured via subjective ratings and electrocortical responses in children (age 10-13) with SAD $(n=28)$, clinical controls with mixed anxiety disorders $(n=28)$, and healthy controls $(n=29)$. Children with SAD showed higher subjective reactivity to the images of angry children's faces while all children reported reduced reactivity in their subjective ratings following reappraisal. Reduced electrocortical reactivity after reappraisal was only evident in older children and boys and was unrelated to anxiety. The present study indicates that cognitive reappraisal may be beneficial in reducing subjective reactivity in children with anxiety disorders, while neural effects of reappraisal may emerge at older ages.
\end{abstract}

Keywords Event-related potentials $\cdot$ Reappraisal $\cdot$ Gender $\cdot$ Emotional face processing $\cdot$ Children $\cdot$ Social anxiety disorder

\section{Introduction}

Social anxiety disorder (SAD) is one of the most prevalent mental disorders in childhood [1,2]. SAD is characterized by an intense fear of negative evaluation, and can result in a significant reduction in quality of life for children [3]. Despite SAD's high prevalence in childhood, the factors supporting the maintenance of the disorder in children are poorly understood [4].

\section{Emotional Reactivity and Regulation in Childhood SAD}

Cognitive models and diagnostic criteria suggest that SAD is maintained by heightened emotional reactivity to social

Julian Schmitz

Julian.Schmitz@uni-leipzig.de

1 Department of Clinical Psychology and Psychotherapy, University of Freiburg, Freiburg, Germany

2 Department of Clinical Child and Adolescent Psychology, Leipzig University, Leipzig, Germany

3 Leipzig Research Center for Early Child Development, Leipzig University, Leipzig, Germany stimuli as a result of biased cognitions, such as distorted appraisals of social situations (e.g. "I am stupid and others don't like me"). In accordance with these theoretical assumptions, several studies of adult SAD populations have found processing biases and enhanced reactivity to socially threatening stimuli such as angry faces (see [5] for a review) as possible maintenance mechanisms. Another key maintenance mechanism may be maladaptive emotion regulation. Research suggests that adults with SAD use maladaptive emotion regulation strategies (e.g. suppression, avoidance) more frequently, while also showing deficits in adaptive emotion regulation strategies such as reappraisal [6]. Research on emotional reactivity and emotion regulation in childhood SAD is scarce. It has been found that children with mixed anxiety disorders (including SAD) show heightened negative subjective responses to threatening images as well as less frequent/less effective use of reappraisal compared to healthy controls [7-9].

When investigating emotional reactivity and regulation, research increasingly employs neural and physiological measures of reactivity and regulation in children. Complementing subjective assessment of emotion regulation in childhood research beyond subjective measures is important, since the validity of self-reports of children can be restricted by lower levels of cognitive-emotional development as well as lower 
self-awareness and may contain significant biases such as memory biases, report tendencies and social desirability [10, 11]. Furthermore, applying neural and physiological measures in childhood psychopathology can shed light on the intriguing question whether biological changes related to psychopathology are present at early stages of disorder development already or whether those changes develop later when disorders become more chronic [12].

Event related potentials (ERPs) have proven particularly useful in this regard, providing a time-sensitive, non-invasive method to elucidate neural correlates of the rapidly unfolding processes of emotion regulation [13, 14]. ERPs have been used to examine the dynamic interplay between bottom-up, stimulus-driven attention to emotional stimuli (i.e. emotional reactivity) and their top-down modulation via regulation strategies. Heightened emotional reactivity, as indexed by elevated ERP responses to emotional stimuli, has been reported in children via early ERP components (P100, N170, EPN) as well as later components such as the P3 and late positive potential (LPP; [15]). To date, however, only a handful of ERP studies have examined emotional reactivity specifically in children with SAD. No differences have been reported between children with SAD and healthy controls via early ERP reactivity in response to emotional faces [16-18]. However, a recent study found enhanced P100 and N170 in children with mixed anxiety disorders (including SAD; [19]). In late ERPs (LPP), by contrast, the findings are also mixed: some studies report increased LPPs in response to threatening faces in children with SAD $[17,18]$ and in mixed anxiety disorder groups (including SAD; [20]), while another study did not find amplified LPPs in response to angry faces in children with SAD [16].

The ERP responses generated when employing emotion regulation strategies, such as reappraisal, are mostly found in later stages of stimulus processing (i.e. during the P3/LPP time window). The LPP was reduced in healthy children when instructed to reappraise by interpreting threatening images as neutral $[21,22]$. This LPP reduction has been thought to reflect successful emotion regulation via reappraisal. Reappraisal ability seems to improve continuously from childhood until early adulthood, likely due to prefrontal cortex maturation [23, 24]. Consequently, studies report linear relationships between enhanced reappraisal-induced LPP modulation and increasing age [22, 25]. Taken together, these results suggest that the LPP can be modulated by reappraisal, particularly in older children, but no study to date has investigated how these effects present in children with SAD.

\section{Limitations of Previous Research and the Present Study}

While previous research has provided important information regarding emotional reactivity and regulation in childhood
SAD, there are several notable limitations, which may also account for some inconsistencies in previous ERP studies on emotional reactivity in childhood anxiety. First, some studies investigated relatively small samples $[17,18]$ and may have been statistically underpowered to capture small or medium sized group differences in neural indices. Furthermore, due to the lack of clinical control groups, little is known about transdiagnostic or disorder-specific effects of emotion regulation processes [26]. The ongoing debate on the universal Research Domain Criteria approach (RDoC; [27]) has led researchers to speculate that different anxiety disorders might share more common biological, cognitive and behavioral maintaining processes than suggested by their distinct classification categories in the DSM-V [28]. For example, Lang et al. [29] found that the physiological reactivity profiles of different anxiety disorders were very similar when anxiety disorders with comparable disorder severity were examined. This calls particularly for the inclusion of clinical control groups (e.g. individuals with mixed anxiety disorders), which can provide more insight into the question if emotional and biological findings are specific for particular anxiety disorders such as SAD or relate more generally to the clinical anxiety spectrum.

Second, some studies investigated a broad age range [7, $8,20]$, which may be problematic since emotional reactivity, emotion regulation and related neural correlates differ considerably between children and adolescents [30, 31]. Third, existing studies with children have investigated ERP reactivity using pictures of adult faces. Evidence suggests that children may process peer and adult emotional faces differently $[32,33]$. When investigating emotional reactivity in response to social threat in childhood SAD, children's faces may have higher salience and more ecological validity since age matched peers are their primary source of social evaluation [34]. Last, most studies on emotional reactivity and emotion regulation in children with anxiety disorders did not consider potential gender differences between boys and girls. This may be problematic, because previous research suggests male and female patients to differ both in terms of their emotional reactivity as well as their ability to regulate emotions including cognitive reappraisal $[35,36]$. Hence, it is conceivable that patients with clinical anxiety do not generally differ from non-anxious groups but that more subtle differences exist specifically between either anxious and non-anxious females or anxious and non-anxious males, which would remain uncovered if gender differences were not taken into account.

The present study is the first to investigate the subjective and electrocortical reactivity to socially threatening children's faces and their modulation through reappraisal in children with SAD. It is also the first study to compare the responses of children with SAD to healthy and clinical control populations (children with mixed anxiety disorders 
(MAD)). First, we hypothesized that children with SAD would show heightened subjective and late ERP reactivity (LPP; $[17,18,20])$ in response to angry faces with socially threatening interpretations, but no differences in early ERPs (P100, N1700, EPN; [16-18]) when compared to HC children. Second, based on previous findings reporting reappraisal difficulties in adult SAD [6], we hypothesized that, compared to HC children, children with SAD would show smaller reappraisal effects on subjective and LPP responses (i.e. smaller reappraisal-related reductions of subjective arousal and LPP amplitudes). Third, we expected reappraisal to be more effective in older children compared to younger children, consistent with the predictions of developmental literature [22, 25]. Since other childhood anxiety disorders (e.g. generalized anxiety disorder, separation anxiety, and specific phobia) have also been characterized by enhanced ERP reactivity in response to threatening faces [20] and reduced reappraisal ability [8], we did not make any predictions for disorder specific outcomes (i.e. difference between SAD and MAD groups). Lastly, we exploratory investigated potential gender differences on subjective and neural reactivity as well as on effects of cognitive reappraisal $[35,36]$.

\section{Methods}

\section{Participants}

Children were recruited for a three-session research project investigating cognitive and behavioral emotion regulation and emotional reactivity in childhood SAD. The final sample consisted of 85 children aged 10-13 years. Participants were recruited through local schools, newspapers and radio advertisements. All participants and their parents provided informed consent. Participants were paid 100 Euro in age-appropriate vouchers upon study completion. Ethical approval was granted by the local ethics committee.

Inclusion criterion for the $\mathrm{SAD}$ group was $\mathrm{SAD}$ as a primary diagnosis $(n=28)$. Children in the MAD clinical control group $(n=28)$ met DSM-5 criteria for separation anxiety disorder $(n=6)$, specific phobia $(n=11)$ or generalized anxiety disorder $(n=11)$ as a primary diagnosis, and they did not have a comorbid SAD. HC children $(n=29)$ did not meet criteria for any lifetime mental disorder. All children were Caucasians. Exclusion criteria for all groups were current or past psychotic episodes, severe major depression, pervasive developmental or neurological disorders and previous or current psychotherapeutic treatment. Diagnostic status of eligible children was assessed by trained graduate students using a modified version of the Anxiety Disorders Interview Schedule for children (Kinder-DIPS; [37]). Parents and children were interviewed separately. All diagnostic sessions were videotaped and supervised by a licensed clinical psychologist. Children also completed the short version of the culture fair intelligence test (CFT-20; [38]).

\section{Psychometric Measures}

Children filled out the Social Phobia and Anxiety Inventory for Children (SPAI-C; [39]), a self-report questionnaire that assesses social fears, and the Fear Survey Schedule for Children (FSSCR; [40]), a self-report measure for different phobic fears. Additionally, children self-reported cognitive, affective and behavioral symptoms of depression by filling out the German version of the Children's Depression Inventory (CDI; [41]). Parents filled out the Child Behavior Checklist (CBCL; [42]), which measures parent's reports of emotional and behavioral problems. Internal consistency for all psychometric measures in the present sample was good to excellent $(\alpha=0.84-0.96)$.

\section{Procedure and Stimuli}

Stimuli were obtained from the Radboud Faces Database (RaFD; [43]) and consisted of 8 Caucasian children (4 boys and 4 girls) with angry facial expressions. Contrary to other studies in the field (e.g. [16]), only pictures of children displaying anger were used. This was done since anger may trigger specifically fear of negative evaluation (e. g. "He is angry with me because I did something wrong"), which is the most relevant emotion leading to enhanced reactivity in SAD children. All stimuli $(1680 \times 1050$ pixels $)$ were displayed in the center of a 22 " computer screen using Presentation software (Neurobehavioral Systems, Albany, California). Stimuli were presented in two experimental conditions. In the reactivity condition, four different pictures of children with angry facial expressions were displayed, and participants were instructed to appraise the stimulus as socially threatening (e.g. “Tom looks angry because he doesn't like you"). In the reappraisal condition, another four different angry children's faces were shown, and participants were instructed to reappraise the face to make the stimulus less socially threatening (e.g. "Max looks angry because of a bad grade. This has nothing to do with you").

The experiment started with a reappraisal training, during which children were introduced to the concept of cognitive appraisal. To ensure that children understood the idea of cognitive appraisal, children had to generate two examples of their own: one where another child looked angry, but this had nothing to with them (reappraisal) and another example where another child looked angry because this child was mad at them (reactivity). Participants then practiced the appraisal task for two trials and rated their arousal (cf. [22]). Following, participants started the 6-block (3 reactivity, 3 reappraisal) task. The conditions were alternated and the condition type in the first block was counterbalanced 


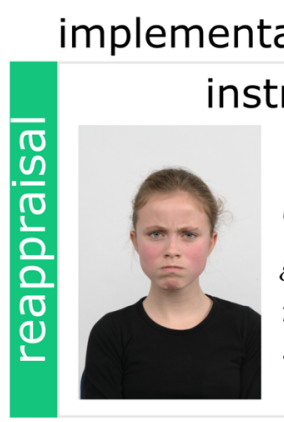

instruction

"Eva looks angry

because of a bad

grade. This has

nothing to do

with you" arousal rating

"How aroused

rould you

feel, if you

met Eva?" application phase

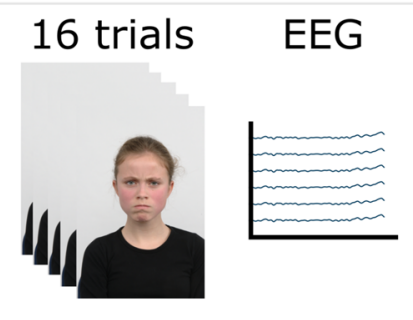

16 trials

EEG

"Nora looks angry

arousal rating

"How aroused

because she doesn't

f would you

feel, if you

met Nora?"

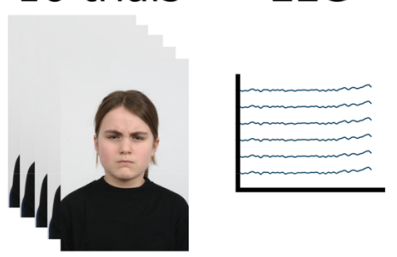

Fig. 1 Reappraisal task. Each block of trials (three blocks per condition) consisted of an implementation phase followed by an application phase. In the implementation phase, children viewed four different angry children's faces and implemented the instructions given for that condition. After each children's face was presented, children

across participants. Each block consisted of an implementation phase and an application phase (see Fig. 1; cf. [44]). During the self-paced implementation phase participants viewed four angry children's faces and applied the instruction given for that condition (reappraisal vs. reactivity). Then, participants rated how aroused they would feel if they met each child on a visual analogue scale $(0=$ not aroused to $100=$ very aroused).

During the application phase, the same four actors shown in that block's implementation phase were presented four times each for $2000 \mathrm{~ms}$ in randomized order (intertrial intervals ranged from 800 to $1200 \mathrm{~ms}$ ) with the restriction of no more than three repetitions of the same stimulus in a row. This resulted in 16 trials per each block and 48 trials per condition. The assignment of stimulus to condition was counterbalanced across participants, thus stimuli in the reappraisal condition were not shown in the reactivity condition and vice versa. As a manipulation check, children evaluated how well they were able to implement the instructions on a 5 -point scale $\left(0=\right.$ not well to $4=$ very well) ${ }^{1}$ To limit circadian influences, all EEG assessments started between 1:00 and 4:30 pm.

\footnotetext{
${ }_{1}$ A univariate analysis of variance (ANOVA) with child gender, age and group as independent variables and children's rating on how well they were able to implement the instruction as dependent variable did not yield any significant effects $(p s>0.152 ; F \mathrm{~s}<2.10)$.
}

rated how aroused they would feel if they were to meet the presented child. In the application phase, the four children's faces from the implementation phase were presented four times each in randomized order, and children continuously applied the instructions from the implementation phase

\section{EEG Recording and Data Reduction}

EEG was recorded from 64 active electrodes of the actiCAP system relative to average reference using a QuickAmp 72 amplifier (Brain Products GmbH, Gilching, Germany) at a continuous rate of $500 \mathrm{~Hz}$. Electrodes were positioned following the 10-20-system. Four electrodes were used to record the electrooculogram (EOG) from positions below and above one eye and from the outer canthi of both eyes. Impedances were kept below $20 \mathrm{k} \Omega$ [45-47].

Offline data processing was performed with EEGLAB [48] and Matlab software. All scalp channels were re-referenced to mathematically linked mastoids. Problematic channels were removed using EEGLAB automatic channel rejection algorithms (EEGLAB function rejchan; spectrum criteria in a range $1-250 \mathrm{~Hz}$ on normalized data with $5 \mathrm{SD}$ threshold). Independent Component Analysis (ICA) was used to computationally remove ocular artifacts. An Infomax algorithm was trained on $4 \mathrm{~s}$ ( -1000 to $3000 \mathrm{~ms}$ ) epochs of $1 \mathrm{~Hz}$ high-pass filtered data after removing noisy epochs using EEGLAB autorej function. SASICA, an EEGLAB 
Fig. 2 Scalp distribution of ERP amplitudes averaged across participants and condition. Circles indicate the electrode clusters used to quantify the ERPs

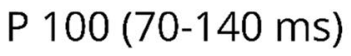

N 170 (140-190 ms)



EPN (240-290 ms)

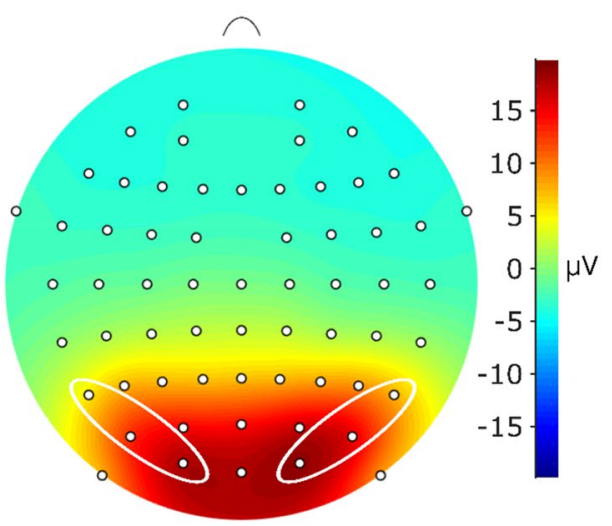



LPP (300-2000 ms)

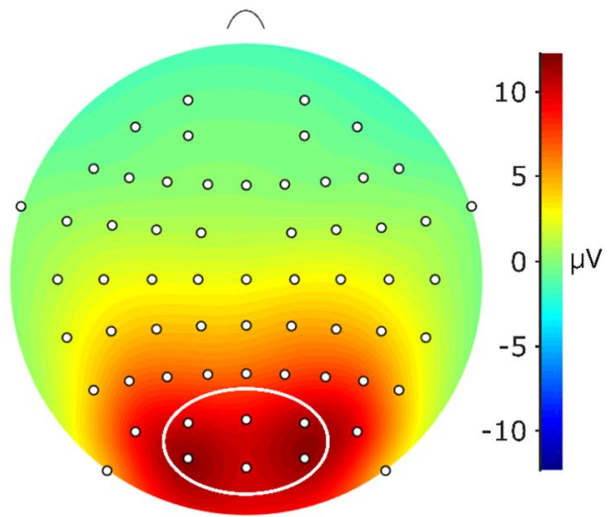

toolbox plug-in, was used for semi-automatic detection of independent components representing ocular artifacts [49] using the ADJUST and EOG correlation methods. The components identified as artifacts by SASICA were individually reviewed and then removed before reconstructing the full length of unfiltered continuous data. The ICA-pruned data was band-pass filtered from 0.1 to $30 \mathrm{~Hz}$ and cut into segments covering -200 to $2000 \mathrm{~ms}$ from stimulus onset (pre-stimulus voltage removed as baseline). Artifacts were identified using the threshold criterion $( \pm 125 \mu \mathrm{V})$. One participant was excluded from analysis due to loss of more than $50 \%$ of trials from one experimental condition. In the final sample, on average $90.72 \%$ ( $S D=10.42 \%$; range $51-100 \%)$ of the epochs were retained. This resulted in at least 23 (on average 43.55) single trials per each mean analyzed in this study, exceeding the recommendation of 8 trials sufficient for obtaining reliable ERP estimates [50]. The epoch retention rate was independent of condition, participant gender, age and group ( $p \mathrm{~s}>0.098$; repeated measures ANOVA). Following [51], we computed Cronbach's alpha estimates for all the ERP components analyzed in this study by treating the average amplitudes for the two conditions as items. Internal consistencies were good to excellent (alpha $=0.81-0.97$ ) and above the recommended ERP reliability threshold (alpha $=0.70 ;[52])$.

ERPs were assessed by separately averaging trials for each condition (reactivity, reappraisal). ERP components were quantified as the mean amplitude $(\mu \mathrm{V})$ in the following electrode positions and time windows, chosen according to previous studies and visual inspection. $\mathrm{P} 100$ at $\mathrm{O} 1, \mathrm{O} 2$ (70-140 ms; [53, 54]). N170 at P7, P8 (140-190 ms; [55, 56]), and EPN at P7, P8, PO7, PO8, O1, and O2 (240-280; $[44,55])$. The LPP was quantified as the mean amplitude at $\mathrm{O} 1, \mathrm{O} 2, \mathrm{Oz}, \mathrm{PO}, \mathrm{PO} 4$ and $\mathrm{POz}$, based on visual inspection of the scalp distribution (see Fig. 2) and previous LPP studies with children [20,56-58]. In accordance with previous child studies (cf. [14, 20, 22, 59]), we analyzed the LPP in three separate time windows at 300-600 ms (early window), 600-1000 ms (middle window) and 1000-2000 ms (late window).

\section{Statistical Analyses}

Children were divided into younger ( $n=44$; mean age 10.9 years, $S D 0.5$ years $)$ and older $(n=41$; mean age 12.7 years, $S D 0.5$ years) groups based on a median split 
Table 1 Sample characteristics

\begin{tabular}{|c|c|c|c|c|c|c|c|c|c|c|}
\hline & \multicolumn{3}{|c|}{$\begin{array}{l}\text { SAD } \\
(n=28)\end{array}$} & \multicolumn{2}{|c|}{$\begin{array}{l}\text { MAD } \\
(n=28)\end{array}$} & & \multicolumn{2}{|l|}{$\begin{array}{l}\mathrm{HC} \\
(n=29)\end{array}$} & \multicolumn{2}{|c|}{ Statistics } \\
\hline & $n$ & & & $n$ & $\%$ & & $n$ & $\%$ & $\begin{array}{l}\chi^{2} \\
(d f=2)\end{array}$ & $p$ \\
\hline \multirow[t]{2}{*}{ Gender (female) } & 22 & & & 13 & 46,43 & & 11 & 37.93 & 10.47 & 0.005 \\
\hline & $M$ & $S D$ & $M$ & $S D$ & $M$ & $S D$ & $F(2,82)$ & & key & $d(95 \% \mathrm{CI})$ \\
\hline Age (years) & 11.81 & 1.17 & 11.93 & 1.00 & 11.69 & 0.83 & $0.40 ; \mathrm{n} . \mathrm{s}$ & . & & \\
\hline CFT-20 & 112.00 & 11.40 & 108.75 & 14.54 & 109.90 & 11.36 & $0.49 ; \mathrm{n} . \mathrm{s}$ & . & & \\
\hline FSSCR & 62.79 & 19.55 & 47.14 & 17.29 & 26.52 & 18.30 & $27.89 * *$ & $\begin{array}{l}\mathrm{S} \\
\mathrm{M} \\
\mathrm{S}\end{array}$ & & $\begin{array}{l}1.92(1.23-2.54) \\
1.16(0.60-1.72) \\
0.85(0.30-1.40)\end{array}$ \\
\hline SPAI-C & 21.61 & 5.95 & 6.24 & 4.39 & 4.84 & 4.27 & $100.71 * *$ & & & $\begin{array}{l}3.25(2.46-4.04) \\
2.94(2.18-3.70)\end{array}$ \\
\hline CDI & 12.32 & 6.86 & 6.89 & 3.14 & 5.34 & 3.98 & $15.70 * *$ & $\begin{array}{l}\mathrm{S} \\
\mathrm{S}\end{array}$ & & $\begin{array}{l}1.25(0.68-1.82) \\
1.02(0.46-1.58)\end{array}$ \\
\hline CBCL Total & 25.29 & 12.81 & 22.36 & 15.39 & 11.44 & 10.99 & $8.39 * *$ & $\begin{array}{l}\mathrm{S} \\
\mathrm{M}\end{array}$ & & $\begin{array}{l}1.16(0.60-1.72) \\
0.82(0.23-1.36)\end{array}$ \\
\hline
\end{tabular}

$M A D$ Mixed Anxiety Disorders including separation anxiety disorder, specific phobia and generalized anxiety disorder, $S A D$ Social Anxiety Disorder, CFT-20 Intelligence Test Short Version, FSSCR Fear Survey Schedule for Children, SPAI-C Social phobia and anxiety inventory for children, $C D I$ Children's Depression Inventory, $C B C L$ Child Behavior Checklist

$* * p<.01 ; * p<.05$

(cf. [21]). Mixed-design ANOVAs were computed to evaluate the effects of each Condition (reactivity, reappraisal) as within-subjects factors and Gender (boys, girls), Age (young, old) and Group (SAD, MAD, HC) as between-subjects factors on subjective and neural outcomes (P100, N170, EPN, LPP). For the LPP, we also included Time (300-600 ms, 600-1000 ms, and 1000-2000 ms) as a within-subjects factor in the analysis. When appropriate Greenhouse-Geisser corrections were applied, in which case corrected $p$-values and degrees of freedom were reported. For the sake of brevity, we report follow-up tests only in case of significant or marginally significant effects involving Group, Age or Gender. In case of significant main effects involving Group, we used post hoc Tukey tests. Simple effects analyses were used for follow-up testing of significant interaction effects. Measures of effect size for ANOVAs are expressed as $\eta_{\mathrm{p}}{ }^{2}$.

\section{Results}

\section{Participant Characteristics}

Sample characteristics are summarized in Table 1. Groups did not significantly differ in age or cognitive abilities ( $p$ s $>0.616)$. As expected, children with SAD had significantly higher scores in social anxiety symptom measures (SPAI-C) than children in HC and MAD groups. The mean
SPAI-C score in the SAD group was above the clinical cutoff $(20 ;[60])$.

\section{Subjective Arousal}

The 3 (Group: SAD, MAD, HC) X 2 (Age: young, old) X 2 (Gender: boys, girls) mixed-design ANOVA showed a marginally significant main effect for Group, $F(2,73)=2.55$, $p=0.085, \eta_{\mathrm{p}}{ }^{2}=0.065: \mathrm{SAD}$ children rated angry children's faces as more arousing in both conditions than $\mathrm{HC}$, $p=0.027, d=0.63$, and also marginally more arousing than MAD children, $p=0.055, d=0.54$, while MAD and HC did not differ from each other, $p=0.960$ (see Fig. 3a). Generally, all children rated the faces in the reactivity condition as more arousing than the faces in the reappraisal condition (see Fig. 3b), as indicated by a significant main effect, $F(1,73)=73.58, p<0.001, \eta_{\mathrm{p}}{ }^{2}=0.502$. As indicated in Fig. $3 c$, girls rated the faces in the reactivity condition as more arousing than boys, $p=0.044, d=0.68$ (no gender differences in the reappraisal condition, $p=0.928$ ), as indicated by a significant interaction between Gender and Condition, $F(1,73)=5.24, p=0.025, \eta_{\mathrm{p}}{ }^{2}=0.067$.

\section{Early ERPs (P100, N170, EPN)}

For each ERP component a 3 (Group: SAD, MAD, HC) X 2 (Age: young, old) X 2 (Gender: boys, girls) mixed-design ANOVA was run. Early ERPs did not differ by Group or 

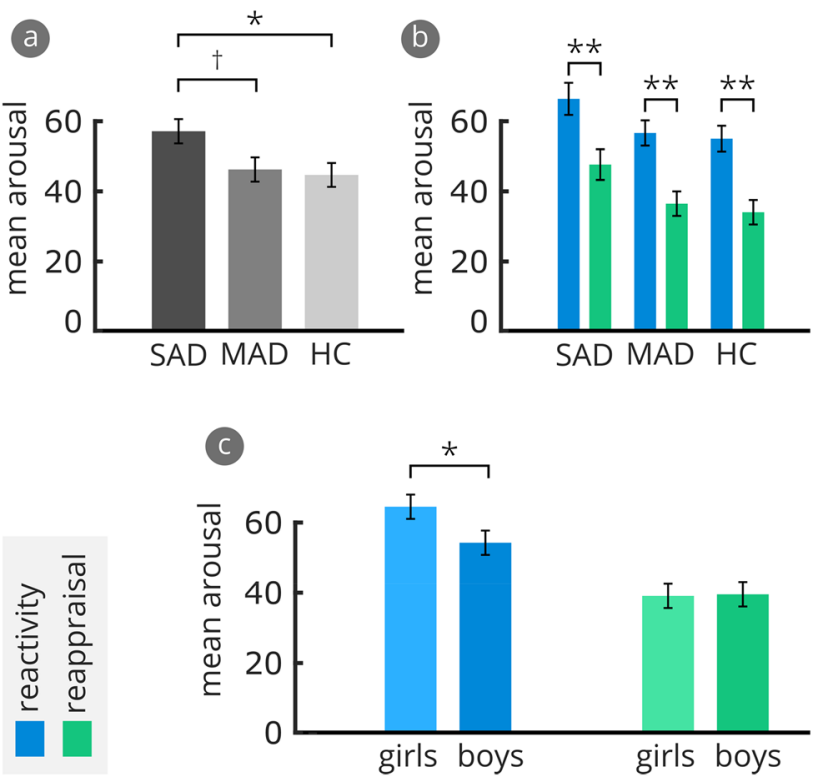

Fig. 3 Subjective Arousal. a Mean arousal to angry children's faces averaged across both conditions separately for each group, b mean arousal separately for the two conditions for each group, c mean arousal separately for the two conditions and for boys and girls. Error bars show standard errors

Table 2 Means and standard deviations of ERP amplitudes in younger and older children

\begin{tabular}{lllllll}
\hline & $\begin{array}{l}\text { Younger } \\
\text { children } \\
(n=44)\end{array}$ & & & \multicolumn{2}{l}{$\begin{array}{l}\text { Older } \\
\text { children } \\
(n=41)\end{array}$} \\
\cline { 2 - 3 } \cline { 5 - 6 } & $M$ & $S D$ & & $M$ & $S D$ \\
\hline P100 & 15.89 & 6.84 & & 11.32 & 6.25 \\
EPN & 13.55 & 4.76 & & 11.24 & 5.30 \\
LPP & 13.23 & 4.98 & & 10.51 & 4.49 \\
\hline
\end{tabular}

Gender, $F s<2.57$, ps $>0.114$. There was a significant main effect for Age on the P100, $F(1,73)=9.49, p=0.003$, $\eta_{\mathrm{p}}{ }^{2}=0.115$, reflecting higher ERP amplitudes in younger children compared to older children. Similarly, younger children showed higher EPN-amplitudes than older children, $F(1,73)=4.89, p=0.030, \eta_{\mathrm{p}}{ }^{2}=0.063$ (see Table 2 ).

\section{Late ERPs (LPP in Three Time Windows: 300-600; 600-1000; 1000-2000 ms)}

The 3 (Group: SAD, MAD, HC) X 2 (Age: young, old) X 2 (Gender: boys, girls) X 3 (Time: $300-600 \mathrm{~ms}, 600-1000 \mathrm{~ms}$, and 1000-2000 ms) mixed-design ANOVA with repeated measures on Time showed no significant effects involving Group, on LPP amplitudes $F s<2.79$, $p s>0.068$. LPP amplitudes differed according to Time, $F(1.43,104.42)=101.85$, $p<0.001, \eta_{\mathrm{p}}{ }^{2}=0.582$, and Age, $F(1,73)=10.48, p=0.002$, $\eta_{\mathrm{p}}{ }^{2}=0.126$. Similar to early ERPs, younger children showed higher LPP amplitudes than older children (see Table 2). Furthermore, Condition interacted with Age, $F(1,73)=6.22$, $p=0.015, \eta_{\mathrm{p}}{ }^{2}=0.079$ and Gender, $F(1,73)=7.94, p=0.006$, $\eta_{\mathrm{p}}{ }^{2}=0.098$ : Older children showed lower LPP amplitudes in the reappraisal condition compared to the reactivity condition, as expected, $p=0.025, d=0.26$. Younger children, by contrast, did not show these differences, $p=0.238$. The Condition X Gender interaction was due to reappraisal effects in boys (irrespective of age), with lower LPP amplitudes in the reappraisal than in the reactivity condition, $p=0.019$, $d=0.38$, but not in girls, $p=0.135$ (see Fig. 4 b). The ERP waveforms in Fig. 4a and c illustrate these two interactions.

\section{Discussion}

The present study is the first to investigate the differences in subjective and cortical responses in children with SAD, healthy controls (HC) and a clinical control group with mixed anxiety disorders (MAD) by means of cognitive appraisals (reactivity, reappraisal). Importantly, all children showed reduced subjective reactivity following reappraisal, supporting cognitive reappraisal as a very beneficial emotion regulation strategy already in children with anxiety disorders. Neurally, a reduced electrocortical reactivity following reappraisal was evident only in older children and in boys. In accordance with our hypothesis, this suggests that the LPP provides a measure of emotion regulation, especially in older pediatric populations. Furthermore, we predicted that, compared to HC children, children with SAD would show increased subjective and late ERP responses to socially threatening children's faces. This hypothesis was partly confirmed, children with SAD showed (a) generally heightened subjective reactivity to angry children's faces in both conditions (reactivity and reappraisal), but (b) no differences in ERPs when compared to HC children. Finally, contrary to our hypothesis, we did not find any differences between $\mathrm{SAD}, \mathrm{MAD}$ or HC groups in reappraisal-related changes of subjective or LPP outcome measures.

\section{Enhanced Subjective Reactivity in SAD Children, But No Clinical Effects on ERP Reactivity or Reappraisal Modulation}

The results showed that children with SAD responded with heightened subjective reactivity in both conditions when compared to $\mathrm{HC}$ and MAD. An overall enhanced subjective reactivity in SAD children indicates that SAD children evaluate an angry looking peer as threatening and that this cannot be fully reduced by means of cognitive appraisal as applied in our brief experimental intervention. Still, cognitive reappraisal had a positive effect on subjective arousal across all participants, including both clinical groups, 

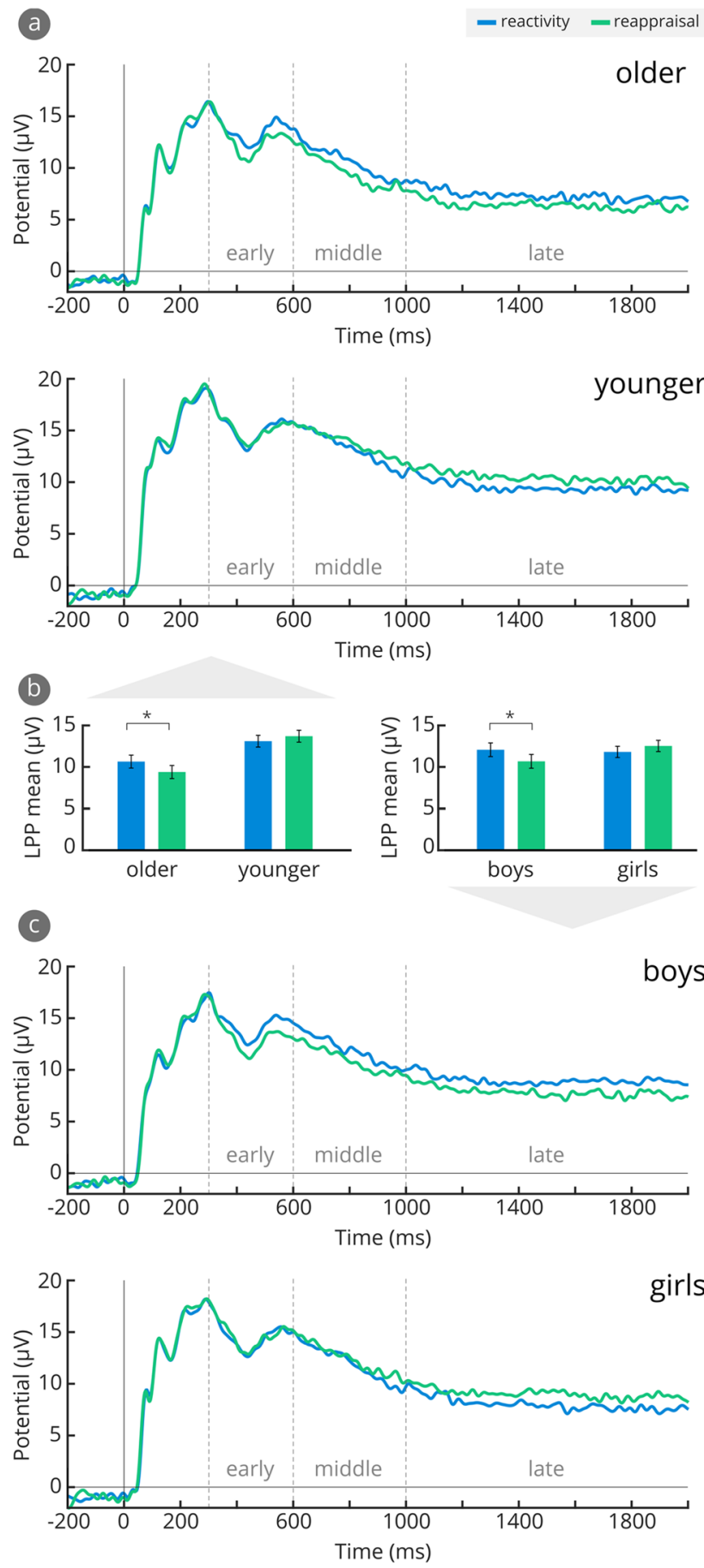

Fig. 4 Cognitive appraisal related effects on LPP (averaged from $\mathrm{Oz}, \mathrm{O} 1, \mathrm{O} 2, \mathrm{POz}, \mathrm{PO} 3$ and PO4). a Stimulus-locked ERPs elicited by socially threatening vs. reappraised angry children's faces across older vs. younger children, b mean LPP amplitudes for socially threatening vs. reappraised angry children's faces across older vs. younger children, and boys vs. girls, $\mathbf{c}$ stimulus-locked ERPs elicited by socially threatening vs. reappraised angry children's faces across boys vs. girls. Error bars show standard errors underpinning its value for addressing negative emotion in childhood anxiety disorders.

Interestingly, the enhanced subjective reactivity in SAD children was not reflected in their ERPs. Such discordance between subjective and neural responses has been seen before, in both children [14] and adults [61]. In addition to the absence of group differences in ERP reactivity, groups did not differ in subjective or electrocortical response modulation using reappraisal. As expected, compared to the reactivity condition, all children reported lower subjective arousal in the reappraisal condition. Yet, this did not translate uniformly to the neural indices since a reappraisalrelated LPP reduction was only present in older children and in boys. Generally, the (dys-)coherence between different emotional subsystems (physiological, experiential, behavioral) can vary by interindividual differences, experimental setups, the type of assessed emotion, psychopathology and by developmental stages of participants [61, 62]. In this line, previous research suggests that neural correlates of emotion (dys-)regulation in anxiety most likely develop at older ages during late childhood and adolescents, leading to discordance between subjective and neural measures in younger samples $[14,25]$, presumably due to brain maturation and increased cognitive control in older children [62]. Taken together, this lack of coherence between subjective and electrocortical measures emphasizes the importance of assessing emotional reactivity and regulation with multiple methods [63] and in samples with a broad age range of children and adolescents to capture potential developmental changes in emotional coherence.

Our study partially replicates, and importantly extends, previous research findings using children's faces as stimuli. Several studies similarly did not find differences between children with SAD and HC in both early [16-18] and late [16] ERP responses to emotional adult faces, while other studies have reported enhanced LPPs in response to threatening adult faces $[17,18,20]$. A previous study found no group differences in habitual use of reappraisal in children with SAD when compared to HC [64, 65], which confirms our clinical null findings. However, the absence of group differences in the effectiveness of reappraisal conflicts with existing studies, which reported reappraisal deficits in older children aged 10-17 with different anxiety disorders, including SAD [7-9]. They also contrast with adult findings suggesting greater reappraisal-related brain activation in controls compared to adults with SAD [66].

The absence of group differences in ERP reactivity and reappraisal modulation might be explained by changes in cognitive and neural development. Reappraisal-related neural activity may be influenced by brain maturation and associated increased cognitive control, working memory and cognitive flexibility [23, 67]. Anatomically, emotion regulation is associated with activity in the prefrontal cortex [68], 
which is one of the last brain structures to develop in adolescence [69]. In the present study, the reappraisal-related LPP activity showed the expected direction only in the older group, which demonstrates that older children are able to accomplish this non-trivial cognitive operation. In line with this finding, several studies did not find reappraisal-induced LPP reductions in younger children aged 5-12 years [22, $25,56,59,70]$. In considering these developmental aspects, it is conceivable that all young children, regardless of their level of anxiety, (a) display bottom-up driven biases towards threatening information [71] and (b) do not show reappraisal modulation in neural components. With increasing age, nonanxious children might learn to inhibit automatic responding to threat by using top-down control strategies, whereas anxious children fail to do so [71, 72]. This might result in group differences in emotional reactivity and regulation with increasing age. Indeed, a recent meta-analysis [72] has found biased processing of threatening stimuli (i.e. enhanced emotional reactivity) in anxious children becomes more evident as children age. This is in accordance with another ERP study which found decreased LPP amplitudes in response to emotional faces with increasing age in controls, but not in SAD children [16]. Possibly, clinical differences in emotional reactivity and reappraisal would only emerge in an adolescent or adult sample.

\section{Reappraising Threatening Faces in Children: Gender Matters}

We found gender effects on reappraisal and reactivity in both subjective and ERP responses. Compared to boys, girls showed higher subjective reactivity when interpreting angry children's faces as socially threatening. Additionally, reappraisal-induced LPP reductions were present in boys but not in girls. Gender-related differences in emotional reactivity and regulation have been reported from previous studies with adult populations (e.g. [73-76]. For example, in a study by McRae et al. [35] men showed lower activity in brain regions related to the use of reappraisal such as the prefrontal cortex when compared to woman. On a subjective level, men and woman were equally able to reduce negative affect towards negative pictures through reappraisal. The authors speculate that male participants may require less cortical effort for the regulation of negative emotion, which would correspond to the findings of our study that only boys showed reappraisal effects on neural activity. Furthermore, girls have often been found to report higher reactivity to negative stimuli and greater difficulties regulating their negative emotions [77-79]. These gender-related differences converge with higher prevalence rates of anxiety and mood disorders in girls [80] suggesting a vulnerability for negative emotions and a difficulty to regulate these. There are also studies reporting gender differences on ERP measures: Girls showed enhanced LPPs to unpleasant and neutral versus pleasant stimuli while boys showed enhanced LPPs to pleasant versus neutral stimuli [81]. Another ERP study showed reduced reappraisal effects on the LPP in younger girls [21]. However, the underlying mechanisms of gender effects in children are still unknown and more research on this topic is clearly needed [82]. A better understanding of gender-related differences in emotion regulation is crucial for informing theoretical models [83], and therapeutic interventions, e.g. by addressing emotion regulation strategies specifically for boys versus girls [77].

\section{Limitations and Future Research}

Our sample size did not allow for specific comparisons between single anxiety disorders (e.g. specific phobia vs. generalized anxiety disorder), which should be further investigated in future studies. Additionally, to evaluate age and gender effects in more detail, future research should include larger samples of girls and boys across a broad age range. Further, since we did not include a neutral baseline condition (e.g. observe, cf. [44]), we do not know whether the subjective hyperreactivity in SAD was due to a generalized reactivity to any kind of social information or due to reporting biases. Last, we cannot rule out that children with SAD reported an elevated subjective reactivity in both conditions of our experiment due to a generally elevated emotional state [84]. This would mean that also neutral and non-social stimuli could have led to reports of enhanced arousal (e.g. "How aroused would you feel if you were alone in your own room at home"). Future studies may therefore want to control for such effects using non-social control stimuli and situations.

In conclusion, the present findings indicate that children with SAD report enhanced subjective reactivity in response to angry children's faces. It appears that LPP modulation can serve as a neural marker of cognitive reappraisal in older children and in boys, regardless of clinical anxiety. Importantly, while previous pediatric SAD research used adult faces, the present study extends previous findings to more salient peer stimuli. The absence of group differences in reappraisal suggests SAD children were just as effective at regulating as $\mathrm{HC}$ and MAD and that changing the affective meaning of social situations is something that patients and controls can accomplish. Thus, rather than addressing putative reappraisal deficits, therapeutic interventions in children with (social) anxiety disorders should target generalized hyperreactivity to social cues.

\section{Summary}

This is the first study known to us which experimentally investigated subjective and neural reactivity to threatening children's faces along effects of cognitive reappraisal in a 
sample of children with SAD, mixed anxiety disorders and healthy controls. Importantly, our results provide evidence, that children with SAD may not only show an enhanced subjective reactivity to social threatening stimuli but that cognitive reappraisal might be an adequate cognitive strategy to counteract dysfunctional threat processing in children. In line with previous studies, no neural correlates of threat processing in clinical anxiety were found in this preadolescent age group. Interestingly, reduced electrocortical reactivity after reappraisal was further only evident in older children and boys and was again unrelated to anxiety. Together with previous research our study therefore suggests that neural correlates of anxiety related threat processing may emerge at later ages of development and that both age and gender of participants may play important influencing factors in this field of research.

Acknowledgements The authors would like to thank the participating children and parents, as well as members of the research project team who facilitated the completion of the study. We would also like to thank Severin Vierrath for his technical and scientific support regarding the EEG data collection and Detlef Caffier for programming the experimental task.

Funding Open Access funding enabled and organized by Projekt DEAL. This work was supported by the German Research Foundation (DFG; TU 78/8-1 and SCHM 3056/2-1). The funding sources had no involvement in the conduct of the research and/or preparation of the manuscript.

\section{Declarations}

Conflict of interest The authors declare that they have no conflict of interest.

Open Access This article is licensed under a Creative Commons Attribution 4.0 International License, which permits use, sharing, adaptation, distribution and reproduction in any medium or format, as long as you give appropriate credit to the original author(s) and the source, provide a link to the Creative Commons licence, and indicate if changes were made. The images or other third party material in this article are included in the article's Creative Commons licence, unless indicated otherwise in a credit line to the material. If material is not included in the article's Creative Commons licence and your intended use is not permitted by statutory regulation or exceeds the permitted use, you will need to obtain permission directly from the copyright holder. To view a copy of this licence, visit http://creativecommons.org/licenses/by/4.0/.

\section{References}

1. Beesdo K, Knappe S, Pine DS (2009) Anxiety and anxiety disorders in children and adolescents: developmental issues and implications for DSM-V. Psychiatr Clin North Am 32(3):483-524. https://doi.org/10.1016/j.psc.2009.06.002

2. Kessler RC, Avenevoli S, Costello EJ, Georgiades K, Green JG, Gruber M et al (2012) Prevalence, persistence, and sociodemographic correlates of DSM-IV disorders in the National
Comorbidity Survey Replication Adolescent Supplement. Arch Gen Psychiatry 69(4):372-380. https://doi.org/10.1001/archg enpsychiatry.2011.160

3. Wittchen HU, Fuetsch M, Sonntag H, Müller N, Liebowitz M (2000) Disability and quality of life in pure and comorbid social phobia: findings from a controlled study. Eur Psychiatry 15(1):4658. https://doi.org/10.1016/S0924-9938(00)00211-X

4. Halldorsson B, Creswell C (2017) Social anxiety in pre-adolescent children: what do we know about maintenance? Behav Res Ther 99:19-36. https://doi.org/10.1016/j.brat.2017.08.013

5. Staugaard SR (2010) Threatening faces and social anxiety: a literature review. Clin Psychol Rev 30(6):669-690. https://doi.org/ 10.1016/j.cpr.2010.05.001

6. Jazaieri H, Morrison AS, Goldin PR, Gross JJ (2014) The role of emotion and emotion regulation in social anxiety disorder. Curr Psychiatry Rep 17(1):531. https://doi.org/10.1007/ s11920-014-0531-3

7. Carthy T, Horesh N, Apter A, Edge MD, Gross JJ (2010) Emotional reactivity and cognitive regulation in anxious children. Behav Res Ther 48(5):384-393. https://doi.org/10.1016/j.brat. 2009.12.013

8. Carthy T, Horesh N, Apter A, Gross JJ (2010) Patterns of emotional reactivity and regulation in children with anxiety disorders. J Psychopathol Behav Assess 32(1):23-36. https://doi.org/ 10.1007/s10862-009-9167-8

9. Legerstee JS, Garnefski N, Jellesma FC, Verhulst FC, Utens EMWJ (2010) Cognitive coping and childhood anxiety disorders. Eur Child Adolesc Psychiatry 19(2):143-150. https://doi. org/10.1007/s00787-009-0051-6

10. Dalgleish T, Taghavi R, Neshat-Doost H, Moradi A, Canterbury R, Yule W (2003) Patterns of processing bias for emotional information across clinical disorders: a comparison of attention, memory, and prospective cognition in children and adolescents with depression, generalized anxiety, and posttraumatic stress disorder. J Clin Child Adolesc Psychol 32(1):10-21. https://doi. org/10.1207/15374420360533022

11. Dadds MR, Perrin S, Yule W (1998) Social desirability and self-reported anxiety in children: an analysis of the RCMAS Lie Scale. J Abnorm Child Psychol 26(4):311-317. https://doi. org/10.1023/A:1022610702439

12. Siess J, Blechert J, Schmitz J (2014) Psychophysiological arousal and biased perception of bodily anxiety symptoms in socially anxious children and adolescents: a systematic review. Eur Child Adolesc Psychiatry 23:127-142. https://doi.org/10. 1007/s00787-013-0443-5

13. Foti D, Hajcak G (2008) Deconstructing reappraisal: descriptions preceding arousing pictures modulate the subsequent neural response. J Cogn Neurosci 20(6):977-988. https://doi.org/ 10.1162/jocn.2008.20066

14. Hajcak G, Dennis TA (2009) Brain potentials during affective picture processing in children. Biol Psychol 80(3):333-338. https://doi.org/10.1016/j.biopsycho.2008.11.006

15. Chronaki G (2016) Event-related potentials and emotion processing in child psychopathology. Front Psychol 7:564. https:// doi.org/10.3389/fpsyg.2016.00564

16. Keil V, Uusberg A, Blechert J, Tuschen-Caffier B, Schmitz J (2018) Facial gender but not emotion distinguishes neural responses of 10- to 13-year-old children with social anxiety disorder from healthy and clinical controls. Biol Psychol 135:36-46. https://doi.org/10.1016/j.biopsycho.2018.02.004

17. Schwab D, Schienle A (2018) Facial affect processing in social anxiety disorder with early onset: evidence of an intensity amplification bias. Soc Neurosci 13(3):318-327. https://doi. org/10.1080/17470919.2017.1304990

18. Schwab D, Schienle A (2017) Facial emotion processing in pediatric social anxiety disorder: relevance of situational 
context. J Anxiety Disord 50:40-46. https://doi.org/10.1016/j. janxdis.2017.05.005

19. Bechor M, Ramos ML, Crowley MJ, Silverman WK, Pettit JW, Reeb-Sutherland BC (2019) Neural correlates of attentional processing of threat in youth with and without anxiety disorders. J Abnormal Child Psychol 47:119-129. https://doi.org/10.1007/ s10802-018-0424-8

20. Kujawa A, MacNamara A, Fitzgerald KD, Monk CS, Phan KL (2015) Enhanced neural reactivity to threatening faces in anxious youth: evidence from event-related potentials. J Abnormal Child Psychol 43(8):1493-1501. https://doi.org/10.1007/ s10802-015-0029-4

21. Dennis TA, Hajcak G (2009) The late positive potential: a neurophysiological marker for emotion regulation in children. $\mathrm{J}$ Child Psychol Psychiatry 50(11):1373-1383. https://doi.org/10. 1111/j.1469-7610.2009.02168.x

22. Van Cauwenberge V, van Leeuwen K, Hoppenbrouwers K, Wiersema JR (2017) Developmental changes in neural correlates of cognitive reappraisal: an ERP study using the late positive potential. Neuropsychologia 95:94-100. https://doi.org/10.1016/j. neuropsychologia.2016.12.015

23. McRae K, Gross JJ, Weber J, Robertson ER, Sokol-Hessner P, Ray RD et al (2012) The development of emotion regulation: an fMRI study of cognitive reappraisal in children, adolescents and young adults. Soc Cogn Affect Neurosci 7(1):11-22. https://doi. org/10.1093/scan/nsr093

24. Silvers JA, McRae K, Gabrieli JD, Gross JJ, Remy KA, Ochsner KN (2012) Age-related differences in emotional reactivity, regulation, and rejection sensitivity in adolescence. Emotion 12(6):1235-1247. https://doi.org/10.1037/a0028297

25. DeCicco JM, O'Toole LJ, Dennis TA (2014) The late positive potential as a neural signature for cognitive reappraisal in children. Dev Neuropsychol 39(7):497-515. https://doi.org/10.1080/87565 641.2014.959171

26. Aldao A (2016) Introduction to the special issue: emotion regulation as a transdiagnostic process. Cognit Ther Res 40(3):257-261. https://doi.org/10.1007/s10608-016-9764-2

27. Insel T, Cuthbert B, Garvey M, Heinssen R, Pine DS, Quinn K et al (2010) Research Domain Criteria (RDoC): toward a new classification framework for research on mental disorders. Am J Psychiatry 167(7):748-751. https://doi.org/10.1176/appi.ajp.2010. 09091379

28. American Psychiatric Association (2013) Diagnostic and statistical manual of mental disorders, 5th edn. American Psychiatric Association, Arlington, VA

29. Lang P, McTeague LM, Bradley MM (2016) RDoC, DSM, and the reflex physiology of fear: a bio-dimensional analysis of the anxiety disorders spectrum. Psychophysiology 53(3):336-347. https://doi. org/10.1111/psyp.12462

30. Eisenberg N, Morris AS (2002) Children's emotion-related regulation. In: Kail RV (ed) Advances in child development and behavior. Academic Press, San Diego

31. Pascalis O, de Vivies XM, Anzures G, Quinn PC, Slater AM, Tanaka JW et al (2011) Development of face processing. Wiley Interdiscip Rev Cogn Sci 2(6):666-675. https://doi.org/10.1002/ wcs. 146

32. Hoehl S, Brauer J, Brasse G, Striano T, Friederici AD (2010) Children's processing of emotions expressed by peers and adults: an fMRI study. Soc Neurosci 5(5-6):543-559. https://doi.org/10. 1080/17470911003708206

33. Marusak HA, Carré JM, Thomason ME (2013) The stimuli drive the response: an fMRI study of youth processing adult or child emotional face stimuli. Neuroimage 83:679-689. https://doi.org/ 10.1016/j.neuroimage.2013.07.002

34. Ferri J, Bress JN, Eaton NR, Proudfit GH (2014) The impact of puberty and social anxiety on amygdala activation to faces in adolescence. Dev Neurosci 36(3-4):239-249. https://doi.org/10. $1159 / 000363736$

35. McRae K, Ochsner KN, Mauss IB, Gabrieli JD, Gross JJ (2008) Gender differences in emotion regulation: an fMRI Study of Cognitive Reappraisal. Group Process Intergroup Relat 11(2):143162. https://doi.org/10.1177/1368430207088035

36. Keil V, Hepach R, Vierrath S, Caffier D, Tuschen-Caffier B, Klein C et al (2018) Children with social anxiety disorder show blunted pupillary reactivity and altered eye contact processing in response to emotional faces: insights from pupillometry and eye movements. J Anxiety Disord 58(8):61-69. https://doi.org/10.1016/j. janxdis.2018.07.001

37. Schneider S, Margraf J (2011) DIPS: Diagnostisches Interview bei psychischen Störungen (4., überarbeitete Auflage). SpringerVerlag, Berlin. https://doi.org/10.1007/978-3-642-15529-1

38. Weiß RH (2006) CFT 20-R: Grundintelligenztest Skala 2-Revision. Hogrefe, Göttingen

39. Beidel DC, Turner SM, Morris TL (1995) A new inventory to assess childhood social anxiety and phobia: the Social Phobia and Anxiety Inventory for Children. Psychol Assess 7(1):73-79. https://doi.org/10.1037/1040-3590.7.1.73

40. Ollendick TH (1983) Reliability and validity of the revised fear survey schedule for children (FSSC-R). Behav Res Ther 21(6):685-692. https://doi.org/10.1016/0005-7967(83)90087-6

41. Kovacs M (1992) Children's depression inventory. Multi-Health System, North Tonawanda, NY

42. Achenbach TM (1991) Manual for the Child Behavior Checklist/4-18 and 1991 profile. University of Vermont Burlington, VT, Department of Psychiatry

43. Langner O, Dotsch R, Bijlstra G, Wigboldus DHJ, Hawk ST, van Knippenberg A (2010) Presentation and validation of the Radboud Faces Database. Cogn Emot 24(8):1377-1388. https:// doi.org/10.1080/02699930903485076

44. Blechert J, Sheppes G, Di Tella C, Williams H, Gross JJ (2012) See what you think: reappraisal modulates behavioral and neural responses to social stimuli. Psychol Sci 23(4):346-353. https://doi.org/10.1177/0956797612438559

45. Junge C, Cutler A, Hagoort P (2012) Electrophysiological evidence of early word learning. Neuropsychologia 50(14):37023712. https://doi.org/10.1016/j.neuropsychologia.2012.10.012

46. Kimura M, Widmann A, Schroger E (2010) Top-down attention affects sequential regularity representation in the human visual system. Int J Psychophysiol 77(2):126-134. https://doi.org/10. 1016/j.ijpsycho.2010.05.003

47. Van Elk M, Bousardt R, Bekkering H, van Schie HT (2012) Using goal- and grip-related information for understanding the correctness of other's actions: an ERP study. PLoS ONE 7(5):e36450. https://doi.org/10.1371/journal.pone.0036450

48. Delorme A, Makeig S (2004) EEGLAB: an open source toolbox for analysis of single-trial EEG dynamics including independent component analysis. J Neurosci Methods 134(1):9-21. https:// doi.org/10.1016/j.jneumeth.2003.10.009

49. Chaumon M, Bishop DVM, Busch NA (2015) A practical guide to the selection of independent components of the electroencephalogram for artifact correction. J Neurosci Methods 250:47-63. https://doi.org/10.1016/j.jneumeth.2015.02.025

50. Moran TP, Jendrusina AA, Moser JS (2013) The psychometric properties of the late positive potential during emotion processing and regulation. Brain Res 1516(6):66-75. https://doi.org/10. 1016/j.brainres.2013.04.018

51. Thigpen NN, Kappenman ES, Keil A (2017) Assessing the internal consistency of the event-related potential: an example analysis. Psychophysiology 54(1):123-138. https://doi.org/10. 1111/psyp.12629

52. Clayson PE, Miller GA (2017) ERP Reliability Analysis (ERA) Toolbox: an open-source toolbox for analyzing the reliability of 
event-related brain potentials. Int J Psychophysiol 111:68-79. https://doi.org/10.1016/j.ijpsycho.2016.10.012

53. Kolassa IT, Miltner WHR (2006) Psychophysiological correlates of face processing in social phobia. Brain Res 1118(1):130-141. https://doi.org/10.1016/j.brainres.2006.08.019

54. Schmitz J, Scheel CN, Rigon A, Gross JJ, Blechert J (2012) You don't like me, do you? Enhanced ERP responses to averted eye gaze in social anxiety. Biol Psychol 91(2):263-269. https://doi. org/10.1016/j.biopsycho.2012.07.004

55. Mühlberger A, Wieser MJ, Herrmann MJ, Weyers P, Troger C, Pauli P (2009) Early cortical processing of natural and artificial emotional faces differs between lower and higher socially anxious persons. J Neural Transm (Vienna) 116(6):735-746. https://doi.org/10.1007/s00702-008-0108-6

56. Babkirk S, Rios V, Dennis TA (2015) The late positive potential predicts emotion regulation strategy use in school-aged children concurrently and two years later. Dev Sci 18(5):832-841. https:// doi.org/10.1111/desc. 12258

57. Kujawa A, Hajcak G, Torpey D, Kim J, Klein DN (2012) Electrocortical reactivity to emotional faces in young children and associations with maternal and paternal depression. J Child Psychol Psychiatry 53(2):207-215. https://doi.org/10.1111/j.1469-7610. 2011.02461.x

58. Kujawa A, Klein DN, Hajcak G (2012) Electrocortical reactivity to emotional images and faces in middle childhood to early adolescence. Dev Cogn Neurosci 2(4):458-467. https://doi.org/ 10.1016/j.den.2012.03.005

59. DeCicco JM, Solomon B, Dennis TA (2012) Neural correlates of cognitive reappraisal in children: an ERP study. Dev Cogn Neurosci 2(1):70-80. https://doi.org/10.1016/j.den.2011.05.009

60. Melfsen S, Florin I, Walter HJ (1999) Die deutsche Fassung des social phobia and anxiety inventory for children (SPAI-C-D): Psychometrische Eigenschaften und Normierung. Diagnostica 45(2):95-103. https://doi.org/10.1026//0012-1924.45.2.95

61. Mauss IB, Levenson RW, McCarter L, Wilhelm FH, Gross JJ (2005) The tie that binds? Coherence among emotion experience, behavior, and physiology. Emotion 5(2):175-190. https://doi.org/ 10.1037/1528-3542.5.2.175

62. Lewis MD, Lamm C, Segalowitz SJ, Stieben J, Zelazo PD (2006) Neurophysiological correlates of emotion regulation in children and adolescents. J Cogn Neurosci 18(3):430-443. https://doi.org/ 10.1162/jocn.2006.18.3.430

63. Zeman J, Klimes-Dougan B, Cassano M, Adrian M (2007) Measurement issues in emotion research with children and adolescents. Clin Psychol (New York) 14(4):377-401. https://doi.org/10. 1111/j.1468-2850.2007.00098.x

64. Asbrand J, Svaldi J, Krämer M, Breuninger C, Tuschen-Caffier B (2016) Familial accumulation of social anxiety symptoms and maladaptive emotion regulation. PLoS ONE 11(4):e0153153. https://doi.org/10.1371/journal.pone.0153153

65. Keil V, Asbrand J, Tuschen-Caffier B, Schmitz J (2017) Children with social anxiety and other anxiety disorders show similar deficits in habitual emotional regulation: evidence for a transdiagnostic phenomenon. Eur Child Adolesc Psychiatry 26:749-757. https://doi.org/10.1007/s00787-017-0942-x

66. Goldin PR, Manber T, Hakimi S, Canli T, Gross JJ (2009) Neural bases of social anxiety disorder: emotional reactivity and cognitive regulation during social and physical threat. Arch Gen Psychiatry 66(2):170-180. https://doi.org/10.1001/archgenpsychiat ry.2008.525

67. Zelazo PD, Carlson SM (2012) Hot and cool executive function in childhood and adolescence: development and plasticity. Child Dev Perspect 6(4):354-360. https://doi.org/10.1111/j.1750-8606. 2012.00246.x

68. Ochsner KN, Gross JJ (2008) Cognitive emotion regulation: insights from social cognitive and affective neuroscience. Curr
Dir Psychol Sci 17(2):153-158. https://doi.org/10.1111/j.14678721.2008.00566.x

69. Gogtay N, Giedd JN, Lusk L, Hayashi KM, Greenstein D, Vaituzis $\mathrm{AC}$ et al (2004) Dynamic mapping of human cortical development during childhood through early adulthood. Proc Natl Acad Sci USA 101(21):8174-8179. https://doi.org/10.1073/pnas.04026 80101

70. Van Cauwenberge V, El Kaddouri R, Hoppenbrouwers K, Wiersema JR (2017) To make a molehill out of a mountain: an ERP-study on cognitive reappraisal of negative pictures in children with and without ADHD. Clin Neurophysiol 128(4):529 537. https://doi.org/10.1016/j.clinph.2017.01.008

71. Field AP, Lester KJ (2010) Is there room for "development" in developmental models of information processing biases to threat in children and adolescents? Clin Child Fam Psychol Rev 13(4):315-332. https://doi.org/10.1007/s10567-010-0078-8

72. Dudeney J, Sharpe L, Hunt C (2015) Attentional bias towards threatening stimuli in children with anxiety: a meta-analysis. Clin Psychol Rev 40:66-75. https://doi.org/10.1016/j.cpr.2015.05.007

73. Bradley MM, Codispoti M, Sabatinelli D, Lang PJ (2001) Emotion and motivation II: sex differences in picture processing. Emotion 1(3):300-319. https://doi.org/10.1037/1528-3542.1.3.300

74. Gardener EKT, Carr AR, MacGregor A, Felmingham KL (2013) Sex differences and emotion regulation: an event-related potential study. PLoS ONE 8(10):e73475. https://doi.org/10.1371/journal. pone. 0073475

75. Lithari C, Frantzidis CA, Papadelis C, Vivas AB, Klados MA, Kourtidou-Papadeli C et al (2010) Are females more responsive to emotional stimuli? A neurophysiological study across arousal and valence dimensions. Brain Topogr 23(1):27-40. https://doi. org/10.1007/s10548-009-0130-5

76. Nolen-Hoeksema S (2012) Emotion regulation and psychopathology: the role of gender. Annu Rev Clin Psychol 8:161-187. https://doi.org/10.1146/annurev-clinpsy-032511-143109

77. Bender PK, Reinholdt-Dunne ML, Esbjørn BH, Pons F (2012) Emotion dysregulation and anxiety in children and adolescents: gender differences. Pers Individ Dif 53(3):284-288. https://doi. org/10.1016/j.paid.2012.03.027

78. Sharp C, van Goozen S, Goodyer I (2006) Children's subjective emotional reactivity to affective pictures: gender differences and their antisocial correlates in an unselected sample of 7-11-yearolds. J Child Psychol Psychiatry 47(2):143-150. https://doi.org/ 10.1111/j.1469-7610.2005.01464.x

79. Suveg C, Zeman J (2004) Emotion regulation in children with anxiety disorders. J Clin Child Adolesc Psychol 33(4):750-759. https://doi.org/10.1207/s15374424jccp3304_10

80. Merikangas KR, He JP, Burstein M, Swanson SA, Avenevoli S, Cui L et al (2010) Lifetime prevalence of mental disorders in U.S. adolescents: results from the National Comorbidity Survey Replication-Adolescent Supplement (NCS-A). J Am Acad Child Adolesc Psychiatry 49(10):980-989. https://doi.org/10.1016/j. jaac.2010.05.017

81. Solomon B, DeCicco JM, Dennis TA (2012) Emotional picture processing in children: an ERP study. Dev Cogn Neurosci 2(1):110-119. https://doi.org/10.1016/j.den.2011.04.002

82. Zahn-Waxler C, Shirtcliff EA, Marceau K (2008) Disorders of childhood and adolescence: gender and psychopathology. Annu Rev Clin Psychol 4:275-303. https://doi.org/10.1146/annurev. clinpsy.3.022806.091358

83. Rutter M, Caspi A, Moffitt TE (2003) Using sex differences in psychopathology to study causal mechanisms: unifying issues and research strategies. J Child Psychol Psychiatry 44(8):1092-1115. https://doi.org/10.1111/1469-7610.00194

84. Asbrand J, Blechert J, Nitschke K, Tuschen-Caffier B, Schmitz J (2017) Aroused at home: basic autonomic regulation during orthostatic and physical activation is altered in children with 
social anxiety disorder. J Abnrom Child Psychol 45(1):143-155. https://doi.org/10.1007/s10802-016-0147-7

Publisher's Note Springer Nature remains neutral with regard to jurisdictional claims in published maps and institutional affiliations. 